ON

\title{
AMPUTATION OF THE LEG
}

\author{
BY A \\ LONG RECTANGULAR FLAP FROM THE CALF.
}

BY

HENRY LEE, F.R.C.S.,

SURGRON TO ST. GEORGE'S HOSPITAL.

Received Feb. 10th-Read May 23rd, 1865.

IN amputation of the leg below the knee Mr. Hey advocated the plan of making a long flap, from the back of the leg. ${ }^{1}$ The large crural nerve in this operation was either left in the flap or had to be dissected out.

Mr. Teale recommends the formation of a long flap from the front of the leg, as forming a covering consisting of parts free from large nerves, and as furnishing the material for a soft cushion movable over the ends of the bones, which enables the patient to bear a part of his weight upon the extremity of the stump. This is a point of great importance where an artificial limb has to be worn, for there can be no doubt, as Mr. Teale has expressed it, that an equal distribution of the pressure between the end of the stump and the upper part of the leg secures the greatest degree of firmness of step.

\footnotetext{
1 'Practical Observations in Surgery,' chap. xxiii.
} 
In the following cases the advantages of a thick flap from the back of the leg, as recommended by Mr. Hey, were combined with the security against any large nerves being left in the extremity of the stump, as in the proceeding recommended by $\mathrm{Mr}$. Teale. In the operation which $I$ perform, the external incisions are made according to Mr. Teale's plan, but the long flap is obtained from the back instead of from the front of the limb, as represented in Fig. 1. Two

\section{Fig. 1.}

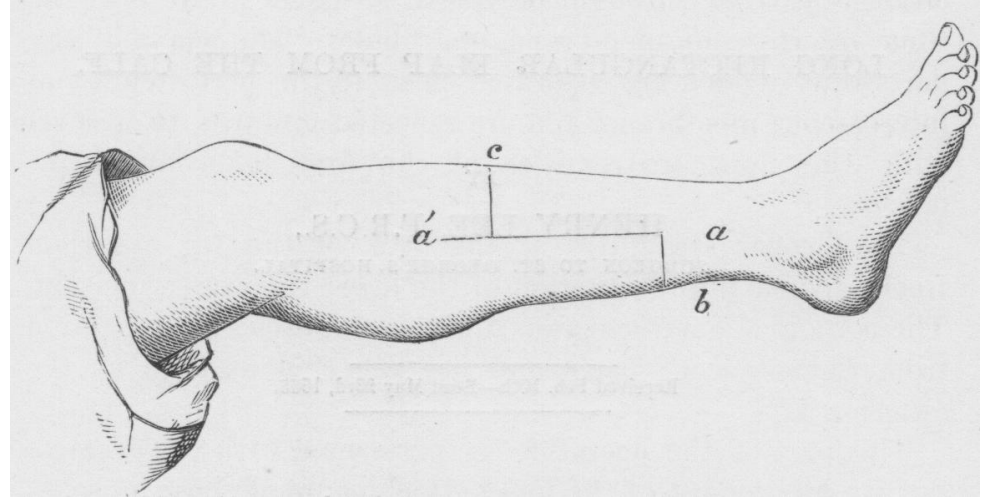

Fig. 1. Showing. lines of external incisions.

$a-a^{\prime}$. Longitudinal incisions.

b. Posterior transverse incisions.

c. Anterior transverse incisions.

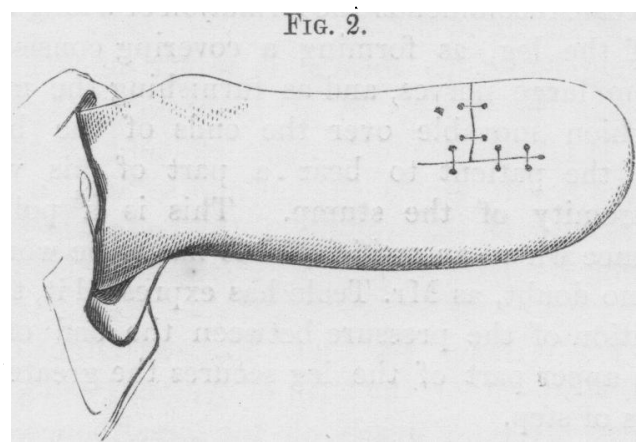

Fig. 2. Showing position of flaps after the operation. 
parallel longitudinal incisions are made along the sides of the leg $\left(a-a^{\prime}\right)$. These are met by a third transverse incision behind $(a-b)$ which joins the lower extremities of the first two. The incisions thus made form three sides of a square, and extend through the skin and cellular tissue only; a fourth incision $(c)$ is made tranversely through the skin in front of the leg, so as to form a flap in this situation one fourth only of the length of the posterior flap. When the skin has become somewhat retracted by its natural elasticity an incision is carried through the parts situated in front of the tibia, interosseous membrane, and fibula. The whole of the parts thus divided are separated close to the periosteum and interosseous membrane, and are reflected upwards to a level with the upper extremities of the first longitudinal incisions.

The deeper structures at the back of the leg are then freely divided in the situation of the lower transverse incision. The conjoined gastrocnemius and soleus muscles are separated from the subjacent parts, and are reflected as high as the anterior flap.

This part of the operation is performed with the greatest facility on account of the loose attachments of these muscles, especially at the lower part of the leg. The deeper layer of muscles, together with the large vessels and nerves, are divided as high as the incisions will permit, and the bones sawn through in the same situation. The flaps are then adjusted as shown in fig. 2.

The long flap thus formed is much thicker than when taken from the front. It is consequently less liable to slough. It affords a much more efficient protection to the ends of the bones, and a thicker and softer pad upon which to rest a part of the weight of the body when an artificial leg is applied.

CASE 1.-William F-, æt. 33, was admitted into St. George's Hospital, on the 24th of August, 1863, with extensive disease involving nearly all the tarsal bones of the right foot, and very seriously impairing his general health. On 
the 17th of October following the leg was amputated by the operation above described. The patient was at the time very greatly debilitated, and his weakness was still further increased by the occurrence of secondary hæmorrhage after the operation, and on the 9th of November by an attack of laryngitis, for which he was placed under the care of Dr. Barclay. He made, however, an excellent recovery, and was enabled to leave the hospital on the 22nd of November.

A drawing of the stump was made on the 26th of November, 1864, at which time he could walk fourteen miles a day upon his artificial leg without inconvenience. He had now learnt to use his leg so well that a casual observer would not remark that there was anything particular in his gait.

CASE 2.-Eliza E-, æet. 21, was admitted into St. George's Hospital, on the 14th of May, 1864, with very extensive disease of the tarsus, for which amputation of the leg was performed, on the 14th of July following, by means of a long rectangular flap from the back.

She was discharged on the 8th of September, with a thick soft cushion moving freely over the extremities of the bones.

On the 10th of December, 1864, the patient was readmitted into the hospital, to have her artificial leg adjusted.

She left the hospital the second time on the lst of February, 1865, and she could then bear the same amount of pressure upon the end of the stump without inconvenience as upon any other part. In walking she habitually rested about half the weight of her body upon the extremity of the stump, and on the 10th of April she could walk three miles in this way with the greatest ease.

CASE 3.-James G-, æt. 39, was admitted into St. George's Hospital, on the 15th September, 1864, both his feet having been run over by a railway train. He had long suffered from disease of the chest, and had lost much blood from the accident before his admission into the hospital. The right leg was removed by a rectangular flap from the back, the left leg by the circular operation. 
A drawing of the stump of the right leg was made on the 26th of November, when it was completely healed. This patient was retained in the hospital until the 14th of December for the adjustment of two artificial legs, with which he walked very comfortably after his return home. The right stump contrasted very favorably in this case with the left, which, however, healed about the same time.

Towards the end of January, 1865, during the very cold weather, this patient was seized with a severe attack of bronchitis, which proved fatal, and a preparation shows the condition of the stump at that period.

In two other cases the operation by a rectangular flap from the calf of the leg has been performed; in one of these the patient recovered speedily and well; in the other, which was a secondary amputation (performed after great loss of blood from ulceration of the anterior tibial artery, and under most unfavorable circumstances), the patient died. ${ }^{1}$ These cases all fell under my own care, and are, I believe, the only ones in which this particular operation has been performed up to the present time.

1 In this case there was extensive and old disease of the bronchial glands, which contained a quantity of matter of the appearance and consistence of putty. 